\title{
Cuantificación en un Camal de Cerdos Seropositivos a Toxoplasma gondii Provenientes de Granjas No Tecnificadas
}

\author{
Frequency in a Slaughterhouse of Seropositive Pigs to Toxoplasma gondii \\ from Non-Technical Pig Farms
}

\author{
Jhon Islachin H. ${ }^{1}$, Francisco Suárez A. ${ }^{2,3}$, Amanda Chávez V. ${ }^{1}$, Eva Casas A. ${ }^{1}$
}

\section{Resumen}

El objetivo del presente trabajo fue determinar en un camal la frecuencia de cerdos con anticuerpos anti-Toxoplasma gondii procedentes de crianzas no tecnificadas y evaluar la variable sexo como factor de riesgo. Se tomaron 240 muestras de sangre de cerdos de un camal de Lima (120 muestras por sexo) y los sueros se evaluaron mediante inmunofluorescencia indirecta (IFI). La frecuencia de cerdos con anticuerpos anti- $T$. gondii obtenida fue de $26.3 \%$, con intervalo de confianza de $95 \%$ entre 20.7 y $31.8 \%$. En el análisis por sexo, el 21.7 de hembras y el $30.8 \%$ de machos fueron reactores a T. gondii. En la prueba del Odds Ratio, la posible asociación del sexo como factor de riesgo obtuvo un valor 1.61, sin significancia estadística.

Palabras clave: cerdos, no tecnificada, toxoplasmosis, IFI, Lima

\section{Abstract}

The aim of this study was to determine the frequency of pigs in a slaughterhouse with antibodies anti-Toxoplasma gondii from non-technical pig farms in Lima, Peru, and to assess the sex as a risk factor. Blood samples $(n=240)$ were collected in a slaughterhouse in Lima (120 samples per sex) and the sera were analyzed by indirect immunofluorescence test (IIFT). The frequency of pigs with antibodies anti-T. gondii was $26.3 \%$, with a confidence interval of $95 \%$ from 20.7 to $31.8 \%$. In the analysis by sex, $26.3 \%$ of females and $30.8 \%$ of males were reactors to $T$. gondii. In the odds ratio test, the possible association of sex as a risk factor showed a non-significant value of 1.61 .

Key words: pigs, non-technical, toxoplasmosis, IIFT, Lima

\footnotetext{
${ }^{1}$ Laboratorio de Microbiología y Parasitología Veterinaria, ${ }^{2}$ Laboratorio de Medicina Veterinaria Preventiva, Facultad de Medicina Veterinaria, Universidad Nacional Mayor de San Marcos, Lima, Perú

${ }^{3}$ E-mail: francisco_suarez2001@hotmail.com
}

Recibido: 17 de octubre de 2015

Aceptado para publicación: 11 de abril de 2016 
La población de ganado porcino en el Perú es de 224300 según el último Censo Agropecuario, donde el $67.2 \%$ son criollos y $32.8 \%$ corresponde a la categoría mejorado (INEI, 2013). Los cerdos criollos pertenecen a pequeños criadores de la sierra y selva, mayormente en crianzas de traspatio, y a criadores de los parques porcinos ubicados en los alrededores de las grandes ciudades. La mayoría de estos últimos son criados en forma libre y con escaso nivel tecnológico, sobre todo, en el aspecto sanitario, donde enfermedades como el cólera porcino y la toxoplasmosis son prevalentes (Ríos et al., 1997).

La toxoplasmosis es la zoonosis por protozoarios más prevalente a nivel mundial y la vía oral es, posiblemente, la principal vía de infección para el humano y los animales, ya sea al consumir carne cruda o mal cocida $\mathrm{o}$ al ingerir alimentos y agua contaminados (Hill y Dubey, 2002).

La frecuencia de cerdos reactores a toxoplasmosis en el Perú ha sido reportada por diversos autores. Así, Vásquez (1988) detectó 45 y $55 \%$ de machos y hembras positivos, respectivamente, Tejada y Balvin (1989) reportaron 59\% de cerdos positivos, en tanto que Suárez et al. (2000) indicaron $32.3 \%$ de cerdos reactores.

La frecuencia de esta zoonosis se ve influenciada por el tipo de crianza de los animales (Aparicio, 1978; Bustamante y Suárez, 2000), donde el cerdo constituye un factor de riesgo de importancia en la transmisión al hombre, especialmente a través de la ingestión de carne o embutidos insuficientemente cocidos (Tenter et al., 2000). Por ello, el presente estudio tuvo como objetivo estimar la frecuencia de cerdos destinados al consumo humano que son reactores a Toxoplasma gondii en la ciudad de Lima, Perú.
Se recolectaron muestras de sangre de cerdos en el Camal Conchucos, ubicado en el distrito de El Agustino, Lima, entre mayo y junio de 2012. Los cerdos eran procedentes de crianzas no tecnificadas de la zona de Lima.

La sangre se recolectó durante el sacrificio de los animales en tubos al vacío y sin anticoagulante. Las muestras fueron conservadas a temperaturas de $4-6{ }^{\circ} \mathrm{C}$ y trasladadas al laboratorio de parasitología de la Facultad de Medicina Veterinaria de la Universidad Nacional Mayor de San Marcos, Lima. Las muestras fueron centrifugadas a $900 \mathrm{~g}$ durante $10 \mathrm{~min}$ y el suero resultante fue almacenado a $-20{ }^{\circ} \mathrm{C}$.

Se utilizó la prueba de inmunoflourescencia indirecta (IFI) para la detección de anticuerpos (IgG) contra Toxoplasma gondii utilizando un kit comercial de detección de toxoplasmosis (VMRD - Veterinary Medical Research \& Development, EEUU). Se siguió el instructivo del kit.

El tamaño mínimo de muestras fue calculado según Daniel (1995) para una expectativa de frecuencia de 0.15 (Bustamante y Suárez, 2000), considerando un error máximo permisible de $5 \%$ y una confianza de $95 \%$. El tamaño de muestra resultante fue de 196; no obstante, se llegó a muestrear 240 animales (120 por sexo) a través de múltiples visitas al camal.

Los resultados son expresados en forma porcentual con sus respectivos intervalos de confianza del $95 \%$, mediante la aproximación normal a la distribución binomial (Berquó et al., 1981). Se evaluó el sexo como factor de riesgo a través de la prueba del Odds Ratio (Daniel, 1995). 


\section{Resultados y Discusión}

Se encontró el $26.3 \%$ de cerdos reactores, siendo de $30.8 \%$ en machos y $21.7 \%$ en hembras (Cuadro 1). Estos hallazgos sugieren la posible presencia de roedores y felinos domésticos en las instalaciones de crianza, así como la posible deficiencia en medidas de higiene y desinfección. En la prueba del Odds Ratio se obtuvo un valor de $\mathrm{OR}=1.61$, con intervalo de confianza de $95 \%$ entre 0.90 y 2.88 .

Cuadro 1. Frecuencia de cerdos reactores a Toxoplasma gondii mediante la prueba serológica de IFI ( $\mathrm{n}=120$ por sexo). Lima, 2012

\begin{tabular}{lcc}
\hline Sexo & $\begin{array}{c}\text { Positivos } \\
(\%)\end{array}$ & IC \\
\hline Macho & 30.8 & $22.6-30.1$ \\
Hembra & 21.7 & $14.3-29.0$ \\
\hline Total & 26.3 & $20.7-31.8$ \\
\hline
\end{tabular}

Resultados similares han sido reportados en Brasil, como es el caso de Millar et al. (2008) y Sousa et al. (2014), donde ambos grupos reportaron $25.5 \%$ de positivos para cerdos muestreados en frigoríficos y en granjas; asimismo, Garcia et al. (1999), en la zona de Paraná, Brasil, reportaron $24 \%$ de cerdos positivos con la prueba de IFI, en animales procedentes de medios rurales. No obstante, seroprevalencias mayores han sido reportadas en Brasil, por ejemplo, $48.5 \%$ en cerdos criados en sistemas semiintensivos (Sousa et al., 2014) y $86.1 \%$ en cerdos de crianzas no tecnificadas (Silva et al., 2000).

Estudios en el Perú, en cerdos criados en las condiciones similares al presente estudio, es decir, en crianza no tecnificada en la zona de Lima, reportan 14.8\% (9.2 $20.4 \%$ ) de cerdos reactores a toxoplasmosis utilizando la prueba de hemaglutinación indirecta (Bustamante y Suárez, 2000). Estos resultados estarían indicando que en esta zona no ha habido mejoras en las medidas de prevención y control, sino que ha habido un incremento en la frecuencia de cerdos afectados en los últimos 15 años.

Los resultados discrepantes se pueden atribuir, además, a factores metodológicos como la prueba diagnóstica utilizada o el punto de corte y a variables ambientales ligadas al manejo higiénico-sanitario (Tsutsui et al., 2003). Asimismo, debe considerarse el tiempo de permanencia de los animales en granja, ya que la probabilidad de exposición al parásito aumenta directamente con la edad (Dubey et al., 1995). Otros motivos que influyen sobre la prevalencia de toxoplasmosis en cerdos están ligados a las costumbres socioculturales, factores geográficos y climáticos (Dubey, 2009).

El resultado del Odds Ratio (1.61) para la posible asociación del sexo con toxoplasmosis fue bajo y sin significancia estadística, indicando que el sexo no constituye factor de riesgo para la adquisición de la toxoplasmosis, resultado que concuerda con otros autores (García et al., 1999; Bustamante y Suárez, 2000; Millar et al., 2008; Sousa et al., 2014).

\section{Conclusiones}

La estimación de la frecuencia para anticuerpos anti-Toxoplasma gondii en cerdos de granjas no tecnificadas en la zona de Lima fue de $26.3 \pm 5.57 \%$ por el método de inmunofluorescencia indirecta (IFI), no encontrándose diferencia estadística para la variable sexo.

\section{Literatura Citada}

1. Aparicio GJ. 1978. Toxoplasmosis. Madrid: Marban: 283 p. 
2. Berquó S, Souza MP, Gotlieb LD. 1981. Bioestatística. São Paulo: Ed EPU. 754 p.

3. Bustamante J, Suárez F. 2000. Estudio comparativo de frecuencias de toxoplasmosis en porcinos procedentes de crianza tecnificada y no tecnificada. Rev Inv Vet Perú 11: 32-39. doi: 10.15381/rivep.v11i1.6782

4. Daniel W. 1995. Bioestadística. Base para el análisis de las ciencias de la salud. México: Ed Limusa. 878 p.

5. Dubey J, Weigel M, Siegel A, Thulliez P, Kitron U, Mitchell M, Mannelli M, et al. 1995. Sources and reservoirs of Toxoplasma gondii infection on 47 swine farms in Illinois. J Parasitol 81: 723-729.

6. Dubey J. 2009. Toxoplasmosis in pigs The last 20 years. Vet Parasitol 164: 89103. doi: 10.1016/j.vetpar.2009.05.018

7. Garcia J, Navarro I, Ogawa L, Oliveira R. 1999. Soroprevalência do Toxoplasma gondii, em suínos, bovinos, ovinos e eqüinos, e sua correlação com humanos, felinos e caninos, oriundos de propriedades rurais do norte do ParanáBrasil. Ciênc Rural 29: 91-97. doi: 10.1590/S0103-84781999000100017

8. Hill D, Dubey JP. 2002. Toxoplasma gondii: transmission, diagnosis y prevention. Clin Microbiol Infect 8: 634640. doi: 10.1046/j.1469-0691.2002.00485.x

9. [INEI] Instituto Nacional de Estadística e Informática. 2013. IV Censo Nacional Agropecuario 2012 (CENAGRO). Banco de datos estadísticos [Internet]. Disponible en: http://proyectos.inei.gob.pe/web/Documentos Publicos/Resultados Finales IV CENAGRO.pdf

10. Millar P, Daguer H, Vicente R, Costa T, Sobreiro L, Amendoeira M. 2008. Toxoplasma gondii: estudo soroepidemiológico de suínos da região $\mathrm{Su}$ - doeste do Estado do Paraná. Pesq Vet Bras 28: 15-18. doi: 10.1590/S0100736X2008000100002

11. Ríos M, Rivera H, Sandoval N, Manchego A, Camacho C, Rosadio $R$. 1997. Asociación del virus del cólera porcino con mortalidad neonatal en crianza porcina no tecnificada. Rev Inv Pec 8: 10-18.

12. Silva R, Bonassi C, Dalla A, Mores NA, Dubey JP. 2000. Serosurvey on pig toxoplasmosis in animals kept in different management systems in Santa Catarina and Rio Grande do Sul states, Brazil. Mem Inst Oswaldo Cruz 95: 147.

13. Souza R, Lemos J, Farias L, Lopes C, dos Santos K. 2014. Seroprevalence and risk factors for Toxoplasma gondii infection in pigs in southern Piauí. Rev Braz Parasitol Vet 23: 98-100.

14. Suárez F, Galisteo A, Hiramoto R, Cardoso R, Meireles L, Miguel $O$, Andrade Jr H. 2000. The prevalence and avidity of Toxoplasma gondii $\mathrm{IgG}$ antibodies in pigs from Brazil and Peru. Vet Parasitol 91: 23-32.

15. Tejada A, Balvin G 1989. Situación actual del estudio de toxoplasmosis en el Perú. En: Anales Seminario Nacional de Zoonosis y Enfermedades de Transmisión Alimentaria. Lima, Perú.

16. Tenter AM, Heckeroth AR, Weiss LM. 2000. Toxoplasma gondii: from animals to humans. Int J Parasitol 30: 1217-1258.

17. Tsutsui V, Navarro I, Freire R, Freitas $J$, Prudencio L, Delbem A, Marana E. 2003. Soroepidemiologia e fatores associados à transmissão do Toxoplasma gondii em suínos do Norte do Paraná. Arch Vet Sci 8: 27- 34. doi: 10.5380/avs.v8i2.4030

18. Vásquez R. 1988. Estudio serológico sobre toxoplasmosis en ganado porcino beneficiado en Lima - Perú, 1985. Tesis de Médico Veterinario. Lima: Univ Nacional Mayor de San Marcos. 43 p. 